\title{
The Effects of TENS Applied to Affected Lower Extremities on Balance in Stroke Patients
}

\author{
Kyu-Ri Lee, PT, PhD, Sang-Hun Jang, PT, $\mathrm{PhD}^{\dagger}$
}

Department of Physical Therapy, Gimcheon University

Received: June 24, 2014 / Revised: July 24, 2014 / Accepted: August 8, 2014

(C) 2014 J Korean Soc Phys Med

\section{| Abstract |}

PURPOSE: This study was to investigate the effectiveness of TENS on balance in stroke patients by analyzing some components such as foot pressure, limit of stability and velocity sway after providing somatosensroy input using TENS.

METHODS: Twenty five subjects participated and were randomly divided into two groups, TENS group $(n=13)$ and control group $(n=12)$ by the computer program. Interventions were given to subjects 5 days a week for four weeks. TENS group were treated with TENS for 60 minutes in addition to the conventional therapy which included 30-minute exercise and rehabilitation ergometer training for 15 minutes. Control group performed only conventional therapy. TENS was applied on the skin of soleus, tibialis anterior, tensor fascia latae and vastus medialis in affected side. Foot pressure, limit of stability and velocity sway for balance test were measured using Biorescue.

RESULTS: TENS group was significantly increased limit of stability and foot pressure in affected side more than control

†Corresponding Author : upsh22@hanmail.net

This is an Open Access article distributed under the terms of the Creative Commons Attribution Non-Commercial License (http://creativecommons.org/licenses/by-nc/3.0) which permits unrestricted non-commercial use, distribution, and reproduction in any medium, provided the original work is properly cited. group. And in eye closed condition, TENS group was significantly decreased velocity sway more than control group.

CONCLUSION: The application of TENS is effective to improve the somatosensory input of affected side and to increase the motor function and balance ability.

Key Words: TENS, Stroke, Balance ability, Somatosensory input

\section{Introduction}

Stroke resulted from the cerebrovascular disorders accompanies deficits of cognition, movement, sensation, perception, speech impediment, depression and the change of personality (Braun et al., 2007). Among those problems, sensory and motor deficits which are the most common feature of stroke can cause the severe problems in asymmetric posture and balance ability (Schmid et al., 2012). Balance ability is necessary for the performance of independent activities of daily living (ADL) and gait. In addition, the biofeedback of somatosensory is indispensable for the balance ability (Bonan et al., 2004).

To improve the balance ability in stroke patients, some interventions such as feedback training using a force plate 
(Cheng et al., 2001), task-related circuit training (Dean et al., 2000), early cycling training (Katz-Leurer et al., 2006) have been conducted and it is reported that additional sensory information could decrease the postural sway and improve the balance in patients with stroke in recent study (Cunha et al., 2012). Priplata et al (2002) reported in his study that the application of imperceptibly mechanical noise stimulation on individual's soles could decrease the postural sway and Gravelle et al (2002) also reported that the application of electrical noise on medial/lateral surfaces of knee joint could reduce the postural sway. That is, the somatosensory input of lower extremities can improve the posture sense and stance stability by stimulating the proprioceptor (Gravelle et al., 2002).

Transcutaneous electrical nerve stimulation (TENS), the most commonly used in physical therapy, is for the pain relief by releasing inhibitory neurotransmitters such as opioids, gamma amino butyric acid (GABA) from the spinal cord, rostral ventromedulla and periaqueductal gray through somatosensroy input (DeSantana et al., 2009; Kalra et al., 2001). However, there are many studies about the change of motor ability by TENS since it becomes known that somatosensory input can influence the motor cortex. Golaszweski et al (1999) reported that the surface electrical stimulation like TENS increases the motor output in healthy adults (Golaszewski et al., 1999) and $\mathrm{Ng}$ and Hui-Chan (2009) also reported that the electrical stimulation facilitates the recovery of motor function (Ng and Hui-Chan, 2009). Moreover, in previous study designed for stroke patients, it is reported that the combined application of surface electrical stimulation and exercise not only effectively improved the strength of dorsiflexor and plantar flexor and gait speed but also reduced the plantarflexor spasticity much more than in the group performing only exercise (Laufer and Elboim-Gabyzon, 2011).

However, the effectiveness of electrical stimulation on the performance of activities is still controversial with some studies reporting electrical stimulation has no therapeutic effect on motor ability. Furthermore, it is insufficient of studies on the balance ability which is closely related with ADL and motor performance (Tong et al., 2006). Thus, this study is to investigate the effectiveness of TENS on balance in stroke patients by analyzing some components such as foot pressure, limit of stability and velocity sway after providing somatosensroy input using TENS.

\section{Method}

\section{Subject}

In this study, subjects who were diagnosed with stroke by neurologists using CT or MRI in M rehabilitation hospital participated in this study after they provided informed consents. The inclusion criteria of this study was as following; 1) more than 6 months for onset, 2) able to maintain the standing position independently for more than one minute, 3) able to perform the independent gait more than $30 \mathrm{~m}, 4)$ no orthopedic disease in lower extremities and trunk, 5) less than G2 spasticity according to modified Ashworth scale, 6) more than 24 scores of MMSE-K, 7) able to cooperate to instructions. In addition, patients who have neurologic, orthopedic disease, aphasia, pacemaker in heart or any wound of applied leg were excluded from this study.

\section{Design}

This was a single-blind, randomized, placebo-controlled, clinical trial. General characteristics of subjects were investigated and physiotherapists who were blinded from the assessment recorded all the demographic data into a computer program designed for stratified randomization. The stratification performed before randomization was based on gender (male and female), side of hemiplegia (left and right). Twenty five subjects participated and were randomly divided into two groups, Control group ( $\mathrm{n}=12)$ and TENS group ( $\mathrm{n}=13)$ by the computer program. 


\section{Intervention}

Interventions were given to subjects 5 days a week for four weeks. TENS group were treated with TENS (DMC, Bio Tron DX, Korea) for 60 minutes in addition to the conventional therapy which included 30-minute exercise and rehabilitation ergometer training for 15 minutes. Control group performed only conventional therapy. Biphasic symmetrical stimulus of which phase duration is $50 \mu \mathrm{s}$ and $70-130 \mathrm{~Hz}$ was used in this study. This frequency modulation was for the prevention of adaptation of sensory system. The stimulus intensity was increased until subjects felt tingling or buzzing feeling in foot and ankle without any muscle contraction or radiation in proximal body segments (Tyson et al., 2013). Furthermore, the intensity was controlled three times in every 15 minute in order to prevent the adaptation. Electrical stimulation was applied on the skin of soleus, tibialis anterior, tensor fascia latae and vastus medialis in affected side. These muscle groups would influence on balance control. Soleus and tibialis anterior are important for ankle stabilization. vastus medialis and tensor fascia latae are also important for knee extension and medial-lateral movement respectively (Worms et al., 2011).

\section{Outcome measures}

All subjects were tested before and after 4-week intervention. Testers were blinded in order to eliminate the possible bias during test. Foot pressure, limit of stability and velocity sway for balance test were measured using Biorescue ( $\mathrm{Rm}$ Ingenierie, France). Biorescue is a measurement device for static and dynamic balance in normal adults, patients and athletes. This device consists of computer, monitor $(93 \times 52 \mathrm{~cm})$ and platform which can measure the pressure force in diverse directions. The platform has 1,600 pressure sensors which can measure the pressure of foot in standing position and movement. Each sensor independently works and the range of pressure measurement is $1 \sim 100 \mathrm{~N} / \mathrm{cm}^{2}$. Subjects were instructed to stand and stare forward on platform with bare feet and then foot pressure of both affected and unaffected side was measured. The velocity sway, moving velocity of center of pressure, was measured in standing position for one minute with both eye-open and eye-closed condition.

Limit of stability is to analyze the maximal limit of maintaining the stability during spontaneous movement in standing position. Subjects were instructed to move their weight toward 8 directions which are left, right, forward, backward, left-forward, left-backward, right-forward and right-backward until maximal range without loss of balance. The distance of movement was analyzed, after separating affected side and non-affected side. The measurements were conducted three times and then the mean value was calculated for statistical analysis. In order to minimize muscle fatigue, 3-minute break was given between measurements.

\section{Data Analysis}

To confirm the homogeneity of subjects, general characteristics such as gender, paretic side and onset type were analyzed using Chi-Square test. In addition, independet t-test was also used to analyze other characteristics such as age, onset period, height and weight. To investigate the effects of TENS on balance of subjects, Paried t-test was used and Independent t-test was also used again to compare the changes of balance ability between groups. The significant level was 0.05 . Data was presented with mean value and standard deviation. PASW 18.0 for window was used for the statistical analysis.

\section{Result}

1. General Features of the Participants of Study

The participants of this study were total of 25 stroke patients, 12 people in the control group and 13 in the 
TENS group, and the gender in the control group were 7 males and 5 females, and 8 males and 5 females in the TENS group, and the average age was 53.42 \pm 9.41 for the control group and $56.46 \pm 10.68$ for the TENS group (Table 1).

\section{Improvement Level Comparison of} Balance Ability of the Two Groups

Foot pressure was significantly increased from $40.19 \pm$ $4.53 \%$ to $44.88 \pm 3.71 \%$ in TENS group and the change in TENS group was more significant than in Control group $(\mathrm{p}<0.05)($ Table 2).

There was no significant difference of limit of stability in non affected side in both groups. However, in affected side, limit of stability was significantly increased from $402.00 \pm 148.81 \mathrm{~mm}^{2}$ to $449.85 \pm 164.73 \mathrm{~mm}^{2}$ in TENS group. Furthermore, the level of increase in TENS was significantly higher than in Control group $(\mathrm{p}<0.05)$ (Table 2$)$.

In terms of velocity sway, although there was a tendency to decrease in eye open condition in TENS group more than control group, it was not statistically significant. In eye closed condition, velocity sway significantly decreased from $.70 \pm .22 \mathrm{~cm} / \mathrm{s}$ to $.55 \pm .19 \mathrm{~cm} / \mathrm{s}$ in TENS group and TENS group showed more significant decrease of velocity sway than Control group $(\mathrm{p}<0.05)($ Table 2$)$.

\section{Discussion}

This study was to investigate the balance ability through the change of foot pressure, limit of stability and velocity sway in stroke patients after providing the input of somatosensory information using TENS.

Stroke patients show the asymmetric posture by supporting just $25 \sim 43 \%$ of weight on affected lower extremity (Yang et al., 2007). In this study, foot pressure in affected side was increased from $40.19 \pm 4.53 \%$ to $44.88 \pm 3.71 \%$ in TENS group which was higher than control group. This result suggests that TENS stimulation which is accompanied with conventional therapy increased the weight shift to affected side in standing position.

Limit of stability in affected side was more increased in TENS group than in control group in this study. This result suggests that TENS is an effective intervention for the weight shift toward affected side. Worm et al (2011) reported that balance ability was improved after the application of electrical stimulus on skin areas of SOL, TA, TFL and VAS in affected side. The improved function of affected lower limbs leads to the integration of movements and the improved coordination in upper limbs. Then, the muscle activation strategy is well developed in order to effectively response to the perturbation of subjects (Worms et al., 2011). In this study, TENS was applied to SOL, TA, TFL and VAS in line with previous study.

Table 1. General characteristics

\begin{tabular}{ccccc}
\hline Variable & Control group $(\mathrm{n}=12)$ & TENS group $(\mathrm{n}=13)$ & $\mathrm{X}^{2} / \mathrm{t}$ & $\mathrm{p}$ \\
\hline Gender (male/female) & $7 / 5$ & $8 / 5$ & .03 & .87 \\
Paretic side (left/right) & $6 / 6$ & $8 / 5$ & .34 & .56 \\
Type of stoke & $9 / 3$ & $7 / 6$ & 1.21 & .27 \\
(hemorrhage/infarction) & & $56.46 \pm 10.68$ & -.75 & .46 \\
Age (years) & $53.42 \pm 9.41^{\mathrm{a}}$ & $15.46 \pm 7.24$ & .67 & .51 \\
Time since stoke (month) & $17.75 \pm 9.65$ & $163.62 \pm 8.21$ & -.28 & .78 \\
Height (cm) & $162.67 \pm 8.86$ & $60.23 \pm 14.34$ & -.45 & .66 \\
Weight (kg) & $57.92 \pm 11.10$ & & & \\
\hline
\end{tabular}

${ }^{\mathrm{a}} \mathrm{Mean} \pm \mathrm{SD}$ 
Table 2. Summary of primary outcome measures at pretest and postest

\begin{tabular}{|c|c|c|c|c|c|c|}
\hline & & & TENS group $(n=13)$ & Control group $(n=12)$ & $\mathrm{t}$ & $\mathrm{p}$ \\
\hline \multirow{4}{*}{$\begin{array}{c}\text { Foot } \\
\text { pressure }(\%)\end{array}$} & \multirow[t]{4}{*}{ Affect } & pret & $40.19 \pm 4.53$ & $43.02 \pm 5.80^{\mathrm{a}}$ & \multirow{4}{*}{-2.14} & \multirow{4}{*}{$.04 *$} \\
\hline & & post & $44.88 \pm 3.71$ & $43.64 \pm 4.76$ & & \\
\hline & & $\mathrm{t}$ & -3.82 & -.47 & & \\
\hline & & $\mathrm{p}$ & $.00 *$ & .65 & & \\
\hline \multirow{8}{*}{$\begin{array}{c}\text { Limit of } \\
\text { Stability }\left(\mathrm{mm}^{2}\right)\end{array}$} & \multirow[t]{4}{*}{ Affect } & pre & $402.00 \pm 148.81$ & $390.25 \pm 156.57$ & \multirow{3}{*}{-2.62} & \multirow{3}{*}{$.02 *$} \\
\hline & & post & $449.85 \pm 164.73$ & $395.58 \pm 161.12$ & & \\
\hline & & $\mathrm{t}$ & -3.52 & -.63 & & \\
\hline & & $\mathrm{p}$ & $.00 *$ & .54 & \multirow{5}{*}{-.41} & \multirow{5}{*}{.69} \\
\hline & \multirow[t]{4}{*}{ Nonaffect } & pre & $585.85 \pm 195.99$ & $553.00 \pm 211.19$ & & \\
\hline & & post & $621.38 \pm 177.34$ & $575.00 \pm 218.44$ & & \\
\hline & & $\mathrm{t}$ & -1.60 & -.89 & & \\
\hline & & $\mathrm{p}$ & .14 & .39 & & \\
\hline \multirow{8}{*}{$\begin{array}{l}\text { Velocity sway } \\
(\mathrm{cm} / \mathrm{s})\end{array}$} & \multirow[t]{3}{*}{$\mathrm{EO}$} & pre & $.54 \pm .26$ & $.50 \pm .30$ & \multirow{2}{*}{.46} & \multirow{2}{*}{.65} \\
\hline & & post & $.46 \pm .22$ & $.46 \pm .21$ & & \\
\hline & & $\mathrm{t}$ & 1.56 & .71 & \multirow{6}{*}{2.41} & \multirow{6}{*}{$.02 *$} \\
\hline & \multirow{5}{*}{$\mathrm{EC}$} & $\mathrm{p}$ & .15 & .49 & & \\
\hline & & pre & $.70 \pm .22$ & $.73 \pm .32$ & & \\
\hline & & post & $.55 \pm .19$ & $.71 \pm .27$ & & \\
\hline & & $\mathrm{t}$ & 3.83 & .19 & & \\
\hline & & $\mathrm{p}$ & .86 & $.00^{*}$ & & \\
\hline \multicolumn{7}{|l|}{${ }^{\mathrm{a} M e a n} \pm \mathrm{SD}$} \\
\hline \multicolumn{7}{|l|}{$* \mathrm{p}<.05$} \\
\hline \multicolumn{7}{|l|}{ EO : eye open } \\
\hline EC : eye close & & & & & & \\
\hline
\end{tabular}

It is believed that the increase of LOS was resulted from the improved capacity of movement of COP by facilitating the coordination between lower extremities and upper extremities with TENS.

There was a tendency for velocity sway to more decrease in TENS group than in control group. Balance is defined as a capacity of maintain the center of gravity within base of support with minimal sway. Thus, postural sway is the main value for the assessment of postural control, balance ability. Postural sway during standing appears by the interaction between the force which interrupt the postural control and postural control system for prevention of the loss of balance. Thus, the increased postural sway means the decreased postural control (Pavol, 2005). In the results of this study, velocity sway tended to decrease in TENS group. This implied that TENS was presented as the effective intervention to improve the postural control.

Especially in this study, TENS group significantly showed more decrease of velocity control group than Control group in eye-closed condition. Cohen et al (1993) reported that normal input of sensory receptor is necessary for the minimal postural sway and stability. Visual, vestibular and somatic sensations are related to postural control (Mergner and Rosemeier, 1998; Smania et al., 2008). Proprioception and vestibular system are more dominant in eye closed condition. Smania et al (2008) reported that balance deficit of stroke patients is resulted from the decreased somatic sensation in lower extremities. According to these previous studies, the reason for the decrease of velocity sway of this study in eye-closed condition is because TENS improved the balance ability by increasing the input of proprioception in lower extremities.

In previous study, it is reported that postural sway was decreased in standing position after the application of TENS in healthy adults (Dickstein et al., 2006). In addition, Pérennou et al (2001) reported the application of TENS 
on neck muscles of stroke patients improved the postural stability in sitting position and $\mathrm{Ng}$ and Hui-Chan (2009) also reported TENS stimulation can improve the gait function and movement patterns which have a relation with balance ability. These previous studies are in line with this study by showing that the stimulation of somatic sensory using TENS can improve the balance ability.

High frequency of TENS has been used for the improvement of motor function of stroke patients in previous study. Dickstein et al (2006) reported postural sway of stroke patients was decreased by applying $100 \mathrm{~Hz}$ and $200 \mu \mathrm{s}$ of TENS using two channels as a sensory threshold to gastrocnemius for 60 minutes. Cho et al (2013) also reported that high frequency TENS of $100 \mathrm{~Hz}$ could decreased the spasticity of gastrocnemius in chronic stroke patients. Furthermore, it is also reported that the decreased spasticity leads to the increased balance by correcting the asymmetric arrangement, resulting in functional improvements and effective energy consumption. In this study, high frequency current, $70-130 \mathrm{~Hz}$ biphasic symmetrical stimulus, was used. The reason for the frequency modulation was to prevent the adaptation of sensory system (Tyson et al., 2013). The improved balance in this study is believed to be a result of the decreased spasticity and improved arrangement by the high frequent TENS.

There are some limitations in this study. The diverse methods of TENS application to improve the balance ability and mobility were not conducted. Furthermore, the kinematics data of upper extremities, lower extremities and pelvis was not investigated in this study. further studies which compensate these limitations will be more helpful to analyze the effects of TENS on the recovery of motor function in diverse directions.

\section{Conclusion}

This study was to investigate the effect of TENS for somatosensroy input on balance ability in 25 stroke patients. Balance components such as foot pressure, limit of stability and velocity sway were measured for analyzing the balance ability of subjects. In the results, TENS addition to conventional therapy was more effective on the increase of foot pressure and limit of stability and the decrease of velocity sway in eye-closed condition. This suggests that the application of TENS is effective to improve the somatosensory input of affected side and to increase the motor function and balance ability.

\section{References}

Bonan IV, Colle FM, Guichard JP, et al. Reliance on Visual Information after Stroke. Part I: Balance on Dynamic Posturography. Arch Phys Med Rehabil. 2004; 85(2):268-73.

Braun SM, Beurskens AJ, van Kroonenburgh SM, et al. Effects of Mental Practice Embedded in Daily Therapy Compared to Therapy as Usual in Adult Stroke Patients in Dutch Nursing Homes: Design of a Randomised Controlled Trial. BMC Neurol. 2007;7(1):34.

Cheng PT, Wu SH, Liaw MY, et al. Symmetrical Body-weight Distribution Training in Stroke Patients and Its Effect on Fall Prevention. Arch Phys Med Rehabil. 2001;82(12):1650-4.

Cho HY, Sung IT, Cho KH, et al. A Single Trial of Transcutaneous Electrical Nerve Stimulation (TENS) Improves Spasticity and Balance in Patients with Chronic Stroke. Tohoku J Exp Med. 2013;229(3): 187-93.

Cohen H, Blatchly CA, Gombash LL.. A Study of the Clinical Test of Sensory Interaction and Balance. Phys Ther. 1993;73(6):346-51.

Cunha BP, Alouche SR, Araujo IMG, et al. Individuals with Post-stroke Hemiparesis are able to Use Additional Sensory Information to Reduce Postural Sway. 
Neurosci Lett. 2012;513(1):6-11.

Dean CM, Richards CL, Malouin F. Task-related Circuit Training Improves Performance of Locomotor Tasks in Chronic Stroke: A Randomized, Controlled Pilot Trial. Arch Phys Med Rehabil. 2000;81(4):409-17. DeSantana JM, Da Silva LFS, De Resende MA, et al. Transcutaneous Electrical Nerve Stimulation at both High and Low Frequencies Activates Ventrolateral Periaqueductal Grey to Decrease Mechanical Hyperalgesia in Arthritic Rats. Neuroscience. 2009;163(4):1233-41.

Dickstein R, Laufer Y, Katz M. TENS to the Posterior Aspect of the Legs Decreases Postural Sway during Stance. Neurosci Lett. 2006;393(1):51-5.

Golaszewski S, Kremser C, Wagner M, et al. Functional Magnetic Resonance Imaging of Human Motor Cortex before and after Whole-hand Afferent Electrical Stimulation. Scand J Rehabil Med. 1999;31(3):165-73.

Gravelle, DC, Laughton CA, Dhruv NT, et al. Noise-enhanced Balance Control in Older Adults. Neuroreport. 2002;13(15):1853-6.

Kalra A, Urban MO, Sluka KA. Blockade of Opioid Receptors in Rostral Ventral Medulla Prevents Antihyperalgesia Produced by Transcutaneous Electrical Nerve Stimulation (TENS). J Pharmacol Exp Ther. 2001; 298(1):257-63.

Katz-Leurer M, Sender I, Keren O, et al. The Influence of Early Cycling Training on Balance in Stroke Patients at the Subacute Stage. Results of a Preliminary Trial. Clin Rehabil. 2006;20(5):398-405.

Laufer Y, Elboim-Gabyzon M. Does Sensory Transcutaneous Electrical Stimulation Enhance Motor Recovery Following a Stroke? A Systematic Review. Neurorehabil Neural Repair 2011;25(9):799-809.

Mergner T, Rosemeier T. Interaction of Vestibular, Somatosensory and Visual Signals for Postural Control and Motion Perception under Terrestrial and Microgravity Conditions-a Conceptual Model. Brain
Res Rev. 1998;28(1-2):118-135.

Ng SS, Hui-Chan CW. Does the Use of TENS Increase the Effectiveness of Exercise for Improving Walking after Stroke? A Randomized Controlled Clinical Trial. Clin Rehabil. 2009;23(12):1093-103.

Pavol MJ. Detecting and Understanding Differences in Postural Sway. Focus on "A New Interpretation of Spontaneous Sway Measures Based on a Simple Model of Human Postural Control". J Neurophysiol. 2005;93(1):20-1.

Pérennou DA, Leblond C, Amblard B, et al. Transcutaneous Electric Nerve Stimulation Reduces Neglect-related Postural Instability after Stroke. Arch Phys Med Rehabil. 2001;82(4):440-448.

Priplata A, Niemi J, Salen M, et al. Noise-Enhanced Human Balance Control. Phys Rev Lett. 2002;89(23):238101.

Schmid AA, Van Puymbroeck M, Altenburger PA, et al. Balance and Balance Self-Efficacy Are Associated With Activity and Participation After Stroke: A Cross-Sectional Study in People With Chronic Stroke. Arch Phys Med Rehabil. 2012;93(6):1101-7.

Smania N, Picelli A, Gandolfi M, et al. Rehabilitation of Sensorimotor Integration Deficits in Balance Impairment of Patients with Stroke Hemiparesis: a Before/After Pilot Study. Neurol Sci. 2008;29(5):313-9.

Tong RK, Ng MF, Li LS. Effectiveness of Gait Training Using an Electromechanical Gait Trainer, With and Without Functional Electric Stimulation, in Subacute Stroke: A Randomized Controlled Trial. Arch Phys Med Rehabil. 2006;87(10):1298-304.

Tyson SF, Sadeghi-Demneh E, Nester CJ. The Effects of Transcutaneous Electrical Nerve Stimulation on Strength, Proprioception, Balance and Mobility in People with Stroke: a Randomized Controlled Cross-over Trial. Clin Rehabil. 2013;27(9):785-91

Worms G, Gollee ZMH, Cikajlo I, et al. Sensory Electrical Nerve Stimulation for Training Dynamic Balance Responses in a Chronic Stroke Patient. J Med Biol Eng. 2011;31(1):19-29. 
Yang YR, Chen YC, Lee CS, et al. Dual-task-related Gait 2007;25(2):185-90.

Changes in Individuals with Stroke. Gait Posture. 